\title{
Difficulties in HAM/TSP diagnosis
}

\author{
Dificuldades no diagnóstico da HAM/TSP \\ Carla Maria Sena Andrade Slater', Luiz Claudio Pereira Ribeiro², Marzia Puccioni-Sohler³
}

\begin{abstract}
The World Health Organization recommends the use of Osame's criterion (1990) for the diagnosis of HTLV-I-associated myelopathy (HAM/TSP). In 2006, a group of neurologists developed a Brazilian criterion that can diagnose HAM/TSP from its onset. Objective: It was to test the agreement between both criteria. Methods: The study included evaluation of clinical and laboratory findings of 35 patients. The ELISA, Western blot and/or polymerase chain reaction was used to search for anti-HTLV-I antibodies. The analysis of agreement was based on the calculation of Kappa. Results: Concordance of 100\% (Kappa=1) occurred in cases of "defined" HAM/TSP, but not in patients with "probable" diagnosis. Conclusion: The Brazilian criteria was as effective as Osame's criteria for the diagnosis of "defined" HAM/TSP. However, both require more specific biological markers in cerebrospinal fluid for the laboratory diagnosis of probable cases.
\end{abstract}

Key words: HAM/TSP, Human T-lymphotropic virus 1, diagnosis.

\section{RESUMO}

A Organização Mundial da Saúde recomenda o uso do critério de Osame (1990) para o diagnóstico da mielopatia associada ao vírus HTLV-I (HAM/TSP). Em 2006, um grupo de neurologistas elaborou um critério brasileiro capaz de diagnosticar HAM/TSP desde suas manifestações iniciais. Objetivo: Foi testar a concordância entre ambos os critérios. Métodos: 0 estudo incluiu a avaliação dos achados clínicos e laboratoriais de 35 pacientes. Os métodos de ELISA, Western blot e/ou reação em cadeia da polimerase foram utilizados para pesquisa de anticorpos anti-HTLV-I. A análise da concordância baseou-se no cálculo do índice Kappa. Resultados: Concordância de 100\% (índice Kappa=1) ocorreu nos casos de HAM/TSP "definida", mas não nos pacientes com o diagnóstico "provável". Conclusão: O critério brasileiro foi tão eficaz quanto o critério de Osame para o diagnóstico de HAM/TSP “definido". No entanto, ambos necessitam de marcadores biológicos mais específicos no líquido cefalorraquidiano para o diagnóstico laboratorial dos casos prováveis.

Palavras-Chave: HAM/TSP, Vírus linfotrópico de células T humanas tipo 1, diagnóstico.

HTLV-I-associated myelopathy (HAM/TSP) is an inflammatory disease of the central nervous system (CNS) with an insidious onset and slowly progressive evolution ${ }^{1}$. The most common neurological manifestations include spastic paraparesis, sphincter dysfunction and sensory impairment. The diagnosis defined by HAM/TSP, according to the Osame criteria (1990), is based on clinical finding and demonstration of anti-HTLV-I antibodies in serum and cerebrospinal fluid $(\mathrm{CSF})^{2-5}$. Castro-Costa et al. elaborated a new diagnosis proposal for HAM/TSP diagnosis, involving a broader evaluation. This model aims at clinical aspects starting at the onset of the disease, including cases of oligosymptomatic disturbances, and additional laboratorial findings attesting the presence of anti-HTLV-I virus proteins (by the Western blot (WB) test and/or polymerase chain reaction (PCR)) in the $\mathrm{CSF}^{6}$.

In endemic areas of HTLV-I infection, the differential diagnosis between myelopathies of unknown origin and HAM/TSP can be difficult, especially in the case of slowly progressive chronic myelopathy, such as the primary progressive type of multiple sclerosis ${ }^{7,8}$.

Due to the difficulty in diagnosing HAM/TSP, its progressive and incapacitating nature, and the comorbidity involved, a more detailed review of the subject proved to be justified. The aim of this study included applying and analyzing the level of concordance between the HAM/TSP diagnosis criteria by Castro-Costa et al. and Osame, evaluating the importance of new criteria for uncertain diagnoses.

\footnotetext{
${ }^{1}$ Neurologist, MD, MSC. Neuroinfection Clinic, Hospital Universitário Gaffrée e Guinle (HUGG), Universidade Federal do Estado do Rio de Janeiro (UNIRIO), Rio de Janeiro RJ, Brazil;

2Pharmaceutic, MSC. Neuroinfection Clinic, HUGG, UNIRIO, Rio de Janeiro RJ, Brazil;

${ }^{3}$ Professor, MD, PhD. Neurologist-Coordinator of the Neuroinfection Clinic, HUGG, UNIRIO; Head of the Cerebrospinal Fluid Laboratory and Clinical Pathology Service, Hospital Universitário Clementino Fraga Filho (HUCFF/UFRJ), Rio de Janeiro RJ, Brazil; Consultant Neurolife Laboratory, Rio de Janeiro RJ, Brazil.

Correspondence: Carla Maria Sena Andrade Slater; Rua Siqueira Campos 43 / sala 1134; 22031-070 Rio de Janeiro RJ - Brasil; E-mail: carla.msas@gmail.com Support: Fundação de Amparo à Pesquisa do Rio de Janeiro (FAPERJ).

Conflict of interest: There is no conflict of interest to declare.
}

Received 23 February 2012; Received in final form 25 April 2012; Accepted 02 May 2012 


\section{METHODS}

\section{Subjects}

This is a transversal and prospective study of $35 \mathrm{pa}-$ tients with neurological signs and/or symptoms compatible with myelopathy diagnosis and seropositive for HTLV-I, seen in the Neuroinfection Clinic of Hospital Universitário Gaffrée e Guinle (HUGG) da Universidade Federal do Estado do Rio de Janeiro (UNIRIO), between March 2007 and March 2010.

All patients were evaluated according to Osame and Castro-Costa et al. criteria for HAM/TSP diagnosis. The Osame criterion considers both slowly progressive paraparesis and anti-HTLV-I antibodies in blood and CSF as "definite", while the "probable" level includes progressive myelopathy in patients with anti-HTLV-I antibodies in serum or CSF, but not in both, or myelopathy that is not consistent with the above description in the presence of anti-HTLV-I antibodies in serum and $\mathrm{CSF}^{2}$. The classification of the "definite" diagnosis by Castro-Costa et al. includes progressive spastic paraparesis that could be associated with sensory and sphincter signs or symptoms, the presence of anti-HTLV-I antibodies in blood and CSF, confirmed by WB and/or positive PCR for HTLV-I in blood and/or CSF. The diagnosis is "probable" if presents monosymptomatic/signs: lower limb spasticity or hyperreflexia or isolated Babinski sign, sensory alterations and anti-HTLV-I antibodies in serum and CSF confirmed by WB and/or positive PCR for HTLV-I in blood and/or $\mathrm{CSF}^{6}$.

\section{Complementary tests}

All patients undertook the following tests: complete blood count $(\mathrm{CBC})$, biochemical profile, rheumatological analysis, thyroid hormones, vitamin B12 and folic acid, HIV serology, hepatitis C and syphilis. The routine CSF analysis included evaluation of cytology, biochemical profile, microbiology, immunology (IgG index and albumin quotient, VDRL). Spinal cord compression was ruled out by image studies.

\section{Screening for HTLV-I}

The serum of all patients was reactive for anti-HTLV-I antibodies by Enzyme-linked immunosorbent assay (ELISA) (Otho HTLV-I, Johnson \& Johnson, New Jersey, USA), confirmed by INNO-LIA ${ }^{\mathrm{TM}}$ HTLVI/II Score (Innogenetics N.V., Belgium). Furthermore, CSF was tested for HTLV-I antibodies by ELISA method, and the positive results were confirmed using WB and/ or PCR. The samples with reactivity to gag p19-I and env gp46-I and/or env gp46-II in the WB were considered positive for HTLV-I. The presence of HTLV-I DNA by PCR was diagnosed when pol or tax sequences were detected in CSF$^{9}$.

\section{Statistical evaluation}

The level of concordance between HAM/TSP diagnostic criteria was also assessed by the kappa index. Numbers varied between zero and one: zero meaning little concordance; 0.41 to 0.60 , moderate concordance; 0.81 to 1 , excellent concordance. The kappa coefficient allows two or more observers to separately classify a sample of objects using the same category scale. The definite levels of Osame and Castro-Costa criteria were compared, and the Kappa value was calculated through the kappa.exe software ${ }^{10}$. The comparison of the probable cases was reported.

\section{RESULTS}

Thirty-five out of 128 (26\%) HAM/TSP patients were followed in the Neuroinfection Clinic and included in the research protocol.

\section{Characteristics of patients with HAM/TSP}

Out of 35 patients with HAM/TSP, 21 were female and median age ( \pm standard deviation $(\mathrm{SD}))$ of $55 \pm 10$ years (Table). Most (60\%) were from the state of Rio de Janeiro, followed by Bahia (14\%) and other states (25.7\%). Muscular weakness in lower limbs was the most common onset symptoms (100\%), followed by sphincter dysfunctions $(71.4 \%)$ and paresthesia in both lower limbs (51.4\%). The current signs and symptoms of the patients are shown in the Figure.

Routine laboratorial tests in serum were normal in all patients, but for the presence of HTLV-I antibodies. The CSF analysis revealed pleocytosis $\left(>4\right.$ cells $\left./ \mathrm{mm}^{3}\right)$ in $57 \%$ of cases, hyperproteinorrachia (protein $>40 \mathrm{mg} / \mathrm{dL}$ ) in $54.2 \%$, IgG index $\geq 7$ (suggests intrathecal IgG synthesis) in $56 \%$ and albumin quotient $\geq 8 \times 10^{-3}$ (indicates dysfunction of the bloodbrain barrier) in $27 \%$. Ninety-four percent (33/35) presented anti-HTLV-I antibodies in CSF by the ELISA method, confirmed by WB and/or PCR.

Table. Demographic data of 35 HAM/TSP patients.

\begin{tabular}{lcc} 
& \multicolumn{2}{c}{ Cases } \\
\cline { 2 - 3 } Characteristics & $\mathrm{n}$ & $\%$ \\
\hline Gender & 14 & 40.00 \\
Male & 21 & 60.00 \\
Female & \\
Age of symptoms onset (years) & $44.54( \pm 13)$ \\
Average (SD) & \multicolumn{2}{c}{45.5} \\
Median & \\
Duration of disease (years) & $10.54( \pm 7.52)$ \\
Average (SD) & \multicolumn{2}{c}{10} \\
Median
\end{tabular}

SD: standard deviation. 


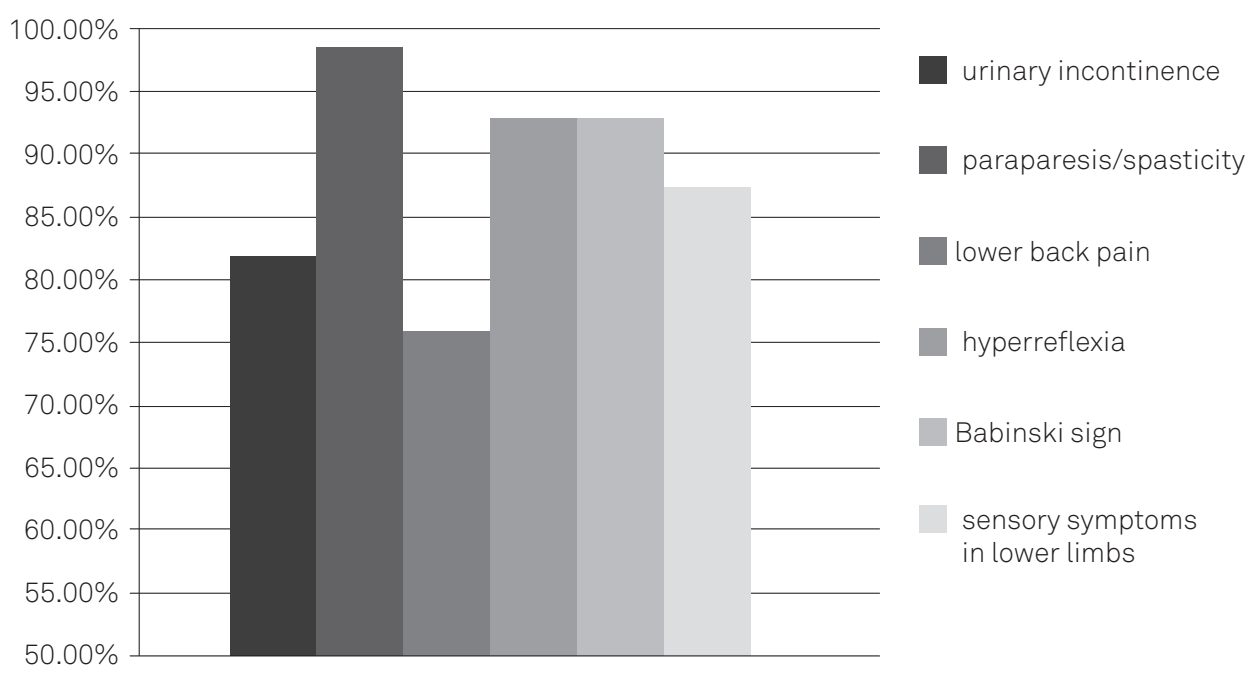

Figure. Current signs and symptoms of the HAM/TSP patients.

\section{Criteria application for HAM/TSP diagnosis}

Out of 35 patients, 32 (91\%) presented "definite" diagnosis, characterized by slowly progressive paraparesis associated with the presence of anti-HTLV-I antibodies in serum and CSF, according to both criteria. The kappa coefficient was equal to 1.0 with complete concordance between criteria for a definite diagnosis. As for the probable diagnosis, one case presented isolated Babinski bilateral sign and anti-HTLV-I antibodies in blood and CSF, fulfilling the Castro-Costa et al. criteria; two other seropositive patients developed slowly progressive spastic paraparesis in the absence of anti-HTLV-I antibodies in CSF, according to the criteria of Osame.

\section{DISCUSSION}

HAM/TSP is a slowly progressive chronic myelopathy, predominating in females in a proportion of $2: 1$ to $3: 1^{11}$. Asymmetric weakness in both lower limbs, lower back pain and urinary incontinence are the most common symptoms. The neurological examination reveals spastic paraparesis associated with pyramidal signs such as hyperreflexia, Babinski and Hoffman signs, and foot clonus. Abnormalities in sensibility may be present, especially in distal region. In our study, we observed a predominance of women (60\%), average age \pm SD of $55 \pm 10$ years, showing weakness in both lower limbs, with the most common alteration being spastic paraparesis. The CSF analysis is, in general, characterized by mild pleocytosis and hyperproteinorrachia, intrathecal synthesis of total $\operatorname{IgG}$ and the presence of HTLV-I antibodies ${ }^{3}$. In addition to these findings, intrathecal production of anti-HTLV-I antibodies occurs in $85 \%$ of patients with HAM/TSP ${ }^{4}$. In our study, we report similar findings.

The defined HAM/TSP classification for both criteria was similar, considering progressive spastic paraparesis as a primordial characteristic for diagnosis, as the demonstration of anti-HTLV-I antibodies in serum and CSF. Our sample consisted of 32 patients presenting a "definite" diagnosis according to Osame and Castro-Costa et al. The kappa index revealed complete concordance between both criteria, indicating that the Castro-Costa et al. criterion was as effective as the Osame criterion for the HAM/ TSP "defined" diagnosis.

As for the "probable" diagnosis of HAM/TSP, we observed that the criterion suggested by Castro-Costa et al. considers clinical findings starting since the emergence of initial manifestations, when patients are oligosymptomatic or present isolated signs, which provides additional data value for HAM/TSP diagnosis. However, verifying anti-HTLV-I antibodies in serum and CSF is also necessary. In our study, one patient presented isolated Babinski sign with anti-HTLV-I antibodies in blood and CSF, thus being classified as "probable" according to the Castro-Costa et al. criterion. The Osame criterion, on the other hand, considers the probability of HAM/TSP diagnosis in the presence of antiHTLV-I antibodies in serum or CSF, since the clinic finding is compatible with progressive myelopathy. Therefore, two patients in our study were classified as "probable" level by the Osame criteria, presenting slowly progressive paraparesis, with reactive anti-HTLV-I antibodies in the blood, but not in the CSF. As a result, the criteria were not concordant for the level of "probable" diagnosis. 
Another aspect related to the Castro-Costa et al. criteria consists of the confirmed presence of antibodies in CSF by WB and/or PCR. The WB analysis represents an important confirmation test for serological diagnosis; however, it is not standardized for use in the CSF. In order to that happens, previous adaptation would be necessary for evaluating intrathecal synthesis of a specific antibody. The demonstration of CSF bands based on the method used in serum may indicate blood-derived viral proteins that cross the blood-brain barrier, which occurs even in normal conditions. Therefore, this evaluation does not display clinic relevance for neurological diagnosis. Furthermore, it is a costly exam, which presents another deterrent of the CSF routine. PCR in the CSF provides additional data in diagnosing HAM/TSP ${ }^{12}$. However, isolated PCR in CSF presents 93\% sensitivity and 85\% specificity (positive predictive value $(\mathrm{PPV})=89$ and negative predictive value $(\mathrm{NPV})=90)$ for the HAM/TSP diagnosis ${ }^{9}$; in other words, positive PCR in CSF does not confirm diagnosis in $100 \%$ of cases, considering the possibility that HAM/TSP patients present negative PCR in CSF, as well as the possibility that patients infected with HTLV-I without HAM/ TSP may have positive PCR for HTLV-I.

There is no diagnosis criterion that includes laboratorial markers capable of differentiating, with 100\% certainty, HAM/TSP from other inflammatory myelopathies. These criteria lack laboratory tests that are able to differentiate HAM/TSP, multiple sclerosis and other neurological diseases in patients infected by HTLV-I. The identification of anti-HTLV-I antibodies in serum and CSF in patients with multiple sclerosis can render more difficult diagnosis, especially in endemic HTLV-I areas. A study in Japan reveals that $2.8 \%$ of HAM/TSP patients are mistakenly diagnosed with multiple sclerosis ${ }^{13}$. The primary progressive types of HAM/TSP and MS are chronic SNC inflammatory diseases, immunomediated, and involve slowly progressive spastic paraparesis associated with sensorial and sphincter dysfunctions. Patients with MS exposed to HTLV-I infection in the past may present anti-HTLV-I antibodies.

As laboratory support, an algorithm that confirms HAM/TSP diagnosis with $100 \%$ probability was proposed. It consists of the combined use of intrathecal synthesis evaluation of anti-HTLV-I antibodies, by the specific antibody index and qualitative PCR in CSF, presenting sensitivity of $74 \%$ and specificity of $100 \%$ (PPV $=100$ and $\mathrm{NPV}=68)^{9}$. Another alternative consists in quantifying the HTLV-I virus in blood and/or CSF, which presents more elevated levels in patients with HAM/TSP compared to asymptomatic individuals ${ }^{14}$. Grassi et al. observed that the ideal viral load in blood, in order to differentiate HAM/ TSP from asymptomatic groups, was 49.865 copies $/ 10^{6}$ PBMC (87\% sensitivity and $81 \%$ specificity) $)^{15}$. In another analysis, the viral load in the CSF contributed to the differential diagnosis of HAM/TSP and multiple sclerosis ${ }^{7}$. The evaluation of the intrathecal synthesis of anti-HTLV-I antibodies and viral load in CSF were also suggested in the laboratorial diagnosis of $\mathrm{HAM} / \mathrm{TSP}^{14}$.

The HAM/TSP diagnosis criteria proposed by CastroCosta et al., similar to that established by Osame, present good applicability for the defined forms. However, the existence of a clinical situation in which patients remain without diagnosis or with doubtful diagnosis demonstrates the need for markers displaying greater sensitivity and specificity in both criteria; in other words, more encompassing and more precise. There is no diagnosis criterion that includes lab markers capable of differentiating HAM/TSP from other myelopathies of inflammatory origin with higher precision. It is necessary to elaborate new diagnosis criteria including more specific parameters, such as the study of viral load and intrathecal synthesis of anti-HTLV-I antibodies, which present increased sensitivity and specificity for HAM/TSP diagnosis.

\section{References}

1. Nakagawa M, Izumo S, ljichi S, et al. HTLV-I associated myelopathy: analysis of 213 patients based on clinical features and laboratory findings. J Neurovirol 1995;1:50-61.

2. Osame M. Review of WHO Kagoshima meeting and diagnostic guidelines for HAM/TSP. In: Blattner W (Ed). Human Retrovirology: HTLV. New York: Raven Press; 1990:191-197.

3. Spina-França A, Livramento JA, Machado LR, Gomes HR. HTLV-I antibodies in serum and cerebrospinal fluid in tropical spastic paraparesis in Brazil. Arq Neuropsiquiatr 1990;48:441-447.

4. Puccioni-Sohler M, Rios M, Bianco C, et al. An inverse correlation of HTLV-I viral load in CSF and intrathecal synthesis of HTLV-I antibodies in TSP/HAM. Neurology 1999;53:1335-1339.

5. Araújo ADQ, Andrada-Serpa MJ. Tropical Spastic Paraparesis/HTLVI-Associated Myelopathy in Brazil. J Acquir Imm Defic Synd Human Retrovirol 1996;13:33-37.
6. Castro-Costa CM, Araújo AQC, Barreto MM, et al. Proposal for diagnostic criteria of tropical spastic paraparesis/HTLV-I-associated myelophaty (TSP/HAM). AIDS Res Human Retrovirus 2006;22:931-935.

7. Thompson AJ, Montalban X, Barkhof F, et al. Diagnostic criteria for primary progressive multiple sclerosis: A position paper. Ann Neurol 2000;47:831-835.

8. Puccioni-Sohler M, Yamano Y, Rios M, et al. Differentiation of HAM/ TSP from patients with multiple sclerosis infected with HTLV-I. Neurology 2007;68:206-213.

9. Puccioni-Sohler M, Rios M, Carvalho S. Diagnosis of HAM/TSP based on CSF proviral HTLV-I DNA and HTLV-I antibody index. Neurology 2001; 57:725-727.

10. Cyr L, Francis K. Measures of clinical agreement for nominal and categorical data: the kappa coefficient. Comput Biol Med 1992;22:239-246. 
11. Moreno-Carvalho AO, Santos JI, Di Gregorio G, Galvão-Castro B. Evidence of preferencial female prevalence of HTLV-I associated tropical spastic paraparesis in Bahia-Brazil. Arq Neuropsiquiatr 1992;50:183-188.

12. Nagai M, Usuku K, Matsumoto W, et al. Analysis Of HTLV-I proviral load in 202 HAM/TSP patients and 243 asymptomatic HTLV-I carriers: high proviral load strongly predisposes to HAM/TSP. J Neurovirol 1998;4:586-593.

13. Kuroda Y, Matsui M, Yukitake M, et al. Assesment of MRI criteria for MS in Japanese MS and HAM/TSP. Neurology 1995;45:30-33.
14. Lezin A, Olindo S, Oliere S, et al. Human T lymphotropic virus type I (HTLV-I) proviral load in cerebospinal fluid: a new criterion for the diagnosis of HTLV-I-associated myelophathy/tropical spastic paraparesis? J Infec Diss 2005;191:1830-1834.

15. Grassi MFR, Olavarria VN, Kruschewsky RA, et al. Human T cell lymphotropic virus type 1 (HTLV-1) proviral load of HTLV-associated myelopathy/tropical spastic paraparesis (HAM/TSP) patients according to new diagnostic criteria of HAM/TSP. J Med Virol 2011;83:1269-1274. 